\title{
Selection and Allocation of a Warehouse Linked to Reloading Terminal and Seaport
}

\author{
Vieroslav Molnar \\ Technical University of Kosice \\ Faculty BERG \\ Institute of Logistics \\ Slovak Republic \\ e-mail: vieroslav.molnar@tuke.sk
}

\author{
Lenka Girovska \\ Technical University of Kosice \\ Faculty BERG \\ Institute of Logistics \\ Slovak Republic \\ e-mail: lenka.girovska@student.tuke.sk
}

\author{
Stanislav Honus \\ Centre ENET \\ VŠB - Technical University of Ostrava \\ Czech Republic \\ e-mail: stanislav.honus@vsb.cz
}

DOI 10.17818/NM/2018/4SI.1

UDK 656.07:656.615

Original scientific paper

Paper accepted: 28. 8. 2018.

\section{Summary}

Combined transport provides great possibilities for material reloading in terminals or warehouses. However, this cannot be done without a tailored warehouse, geographically suitable for all stakeholders, technically adequate for the handled material, providing the required service while keeping the transport costs at minimum. Allocation design and warehouse erection, connecting the warehouse with the reloading terminal - the seaport, provides an ever-increasing number of options and solutions in the form of integrated freight trains and regular container trains linking seaports with reloading terminals, which significantly saves transport costs and allows for more route and transport type combinations. The paper presents how a suitable warehouse is selected and how its allocation is decided on to cater to transport of the material through the reloading terminal and the seaport. Warehouse allocation was proposed using the Cooper iteration method. The given warehouse location will ensure the optimal cost of shipping and deliveries to individual customers.

\section{INTRODUCTION}

In today's world of efficient production, companies choose a mode of transport that will bring the best value for business at the end of the process. Contemporary production processes are characterizedby the global supply chains, short life cycles and growing personalization of goods [1]. All transport options should be considered prior to carrying out the shipment, as should be the type of transport vehicles and the transport route. Selected options must be in line with customer requirements, which are becoming increasingly demanding, translating into more complicated shipping requirements [2]. It is often necessary to use complex solutions and shipping combinations [3].

To do this, a warehouse whose functions cater to this service needs to be supplied. It is necessary to take into account the properties of the material that directly affect the requirements for storage properties and conditions. The warehouse plays an important role on the material's path from the manufacturer to the consumer, i.e. the customer. The impact of the warehouse on the material quality, transportation costs and demanding delivery options, involving a large number of customers and the diversity of their individual requirements, is far from negligible [4]. A technically well-prepared warehouse, i.e. such equipped with the required handling technology, ensures timely and flexible deliveries of exact volumes the customer needs at the given moment.

To achieve a combined transportation position on the domestic and international markets, rational management, quality and mutual cooperation of all modes of transport are a must [5]. Provision of combined transport of high quality depends on the quality of all related services [6]. Since combined transport consists of at least two types of transportation, at one point, the goods will need to be reloaded from one type of vehicle to another [7]. Provision of suitable means of transport is not sufficient, as the selection of the reloading terminal or the warehouse where the reloading takes place affect the quality of combined transport in equal way. Therefore, the warehouse allocation with a link to the reloading terminal - the seaport, is an important requirement with regard to the geographic location of customers. This also closely relates to the technical possibilities of warehouse equipment with the aim to meet customer requirements for the supply of goods [8].

Designing and delivering a suitable warehouse, whose activities will contribute to quality, timely, flexible and costeffective delivery, while taking into account all requirements by the customer as well as by the manufacturer, is not easy. 
For the correct selection, the analysis of sales and of the used transport and warehouses need to be made. Based on the results of the analysis and after the implementation of the iterative algorithm for the allocation of the warehouse, the optimal way of choosing a suitable warehouse for customers of a single territory is selected [9]. A forecast of the used transport modes is employed to better illustrate the need to use the combined transport warehouses in the future.

The growing volume of road transport creates a negative impact on the environment, which forces us to look for new opportunities and solutions. The advanced production and consumption prompt equal development in the field of transport. Its quality depends on the speed, accuracy, reliability, price, time of the goods delivery using modern means and equipment. All activities, however, must protect and conserve the nature and not pose a threat to it.

Increased interest in the environmental aspect of transportation has brought about a development of thus stimulated combined transportation in Europe. Increased volume of road freight transport in Europe has had a negative impact on the environment and has stimulated measures to reduce this impact [10] particularly in fossil energy use, capital and labour relations. The authors have investigated the transport related fossil fuel consumption $2003-2010$ in a macroeconomic context in Hungary and Germany. The Cobb-Douglas type of production function could be justified empirically, while originating from the general CES (Constant Elasticity of Substitution. Individual EU countries have begun to favor the use of combined transportation as its impact on the environment is less harmful than the impact of the road transportation. It also provides reliability, safety and efficiency of transport with elimination of adverse environmental impacts. It is accomplished by cumulating of all kinds of transport, i.e. water, road, and rail.

It is rather difficult for the combined transport to compete with continental road freight traffic in the inland European countries. Its share does not account for more than one tenth. International transport accounts for more than a half of this figure. If strong growth rates are maintained in the coming years, experts estimate that in 2020, its share in Europe may reach two-fifths of its present level [11].

\section{CURRENT STATE OF WAREHOUSE USE IN THE SYSTEM OF COMBINED TRANSPORT OPERATION}

Since each combined transport is made up of a combination of at least two modes of transport, material must be reloaded from one vehicle type to another. Reloading occurs in warehouses, where the material is reloaded directly to another vehicle or is stored in a warehouse and transported subsequently on the basis of a customer's request.

A very important role in combined transport is played by material reloading and its storage in different types of warehouses. The use of warehouses depends on the requirements for delivery of the material to the customer and on a variety of conditions. Warehouses feature a varying degree of equipment, options and conditions. Not every warehouse is suitable for storing or reloading just about any material. Wrongchoices lead to increased storage and shipping costs as well as higher risk of material damage. The paper describes how to optimize product storage during combined transport, determined by three different methods of assessment.

\section{OPTIMAL PRODUCT STORAGE ANALYSIS}

Combined transportation of products necessitates the selection of a suitable warehouse, which would best meet the transport and customer requirements [12].

3 different methods of analysis have been chosen:

Weighted sum method,

DMM method,

FDMM method [13].

Criteria in Table 1 have been selected for the assessment of shipments to individual $A, B, C$ warehouses and for the assessment of material storage conditions in those warehouses.

\section{WEIGHTED SUM METHOD}

The principle of this method of assessment lies in determining the weights for individual criteria, determining the weights for warehouse alternatives and in subsequent calculation of the total utility of individual alternatives. Table 2 presents the results of the assessment by weighted sum method using the proposed criteria and the individual weight allocation.

After making the weighted sum calculations, the results show that the best alternative for the given shipment is the $A$ warehouse.

\section{DMM METHOD}

Table 3 shows the results of the second method of assessment. It uses the proposed assessment criteria and allocates the individual weights. Table 3 leads to the conclusion that the optimal warehouse is the A warehouse.

Table 1 Criteria for assessing shipments to individual warehouses

\begin{tabular}{|l|c|c|c|}
\hline Criteria & Warehouse A & Warehouse B & Warehouse C \\
\hline K1 - Warehouse location with respect to the customer & $30 \mathrm{~km}$ & $35 \mathrm{~km}$ & $25 \mathrm{~km}$ \\
\hline K2 - Available infrastructure & excellent & sufficient & good \\
\hline K3 - Technical equipment of the warehouse & excellent & poor & excellent \\
\hline K4 - Transportation options & excellent & good & good \\
\hline K5 - Shipment time and flexibility & 24 hours & $24 \div 36$ hours \\
\hline K6 - Transport costs & excellent & excellent & excellent \\
\hline K7 - Storage costs & excellent & good & very good \\
\hline
\end{tabular}

Source: authors 
Table 2 Results of the assessment by the weighted sum method

\begin{tabular}{|l|c|c|c|c|c|c|c|}
\hline Criteria & Weights & \multicolumn{2}{c|}{ Warehouse A } & \multicolumn{2}{c|}{ Warehouse B } & \multicolumn{2}{c|}{ Warehouse C } \\
\hline K1 - Warehouse location with respect to the customer & 0.05 & 5 & 0.25 & 3 & 0.15 & 8 & 0.40 \\
\hline K2 - Available infrastructure & 0.10 & 9 & 0.90 & 3 & 0.30 & 8 & 0.80 \\
\hline K3 - Technical equipment of the warehouse & 0.25 & 9 & 2.25 & 3 & 0.75 & 9 & 2.25 \\
\hline K4 - Transportation options & 0.20 & 9 & 1.80 & 9 & 1.80 & 9 & 1.80 \\
\hline K5 - Shipment time and flexibility & 0.20 & 9 & 1.80 & 8 & 1.60 & 6 & 1.20 \\
\hline K6 - Transport costs & 0.10 & 8 & 0.90 & 5 & 0.50 & 7 & 0.70 \\
\hline K7 - Storage costs & 0.10 & 9 & 0.90 & 4 & 0.40 & 7 & 0.70 \\
\hline Sum & $\Sigma 1.00$ & & 8.80 & & 5.50 & \\
\hline Final order & & & 1 & & 3 & & 2 \\
\hline
\end{tabular}

Source: authors

Table 3 Results of the assessment by the DMM method

\begin{tabular}{|c|c|c|c|c|c|c|c|}
\hline \multirow{2}{*}{ Criteria } & \multirow{2}{*}{$\begin{array}{l}\text { Weights } \\
\text { aj }\end{array}$} & \multicolumn{2}{|c|}{ Warehouse A } & \multicolumn{2}{|c|}{ Warehouse B } & \multicolumn{2}{|c|}{ Warehouse C } \\
\hline & & u1 & a1.u1 & $u 2$ & $a 2.42$ & u3 & a3.u3 \\
\hline $\begin{array}{l}\text { K1 - Warehouse location with respect to the } \\
\text { customer }\end{array}$ & 4 & 6 & 24 & 4 & 16 & 8 & 32 \\
\hline K2 - Available infrastructure & 5 & 9 & 45 & 3 & 15 & 8 & 40 \\
\hline K3 - Technical equipment of the warehouse & 8 & 9 & 72 & 3 & 24 & 8 & 64 \\
\hline K4 - Transportation options & 6 & 9 & 54 & 7 & 42 & 8 & 48 \\
\hline K5 - Shipment time and flexibility & 7 & 9 & 63 & 8 & 56 & 6 & 42 \\
\hline K6 - Transport costs & 8 & 9 & 72 & 6 & 48 & 8 & 64 \\
\hline K7 - Storage costs & 9 & 9 & 81 & 4 & 32 & 7 & 63 \\
\hline Sum & $\Sigma 48$ & \multicolumn{2}{|c|}{411} & \multicolumn{2}{|c|}{233} & \multicolumn{2}{|c|}{353} \\
\hline Final order & & \multicolumn{2}{|r|}{1} & \multicolumn{2}{|c|}{3} & \multicolumn{2}{|r|}{2} \\
\hline
\end{tabular}

Source: authors

After making the weighted sum calculations, the results show that the best alternative for the given shipment is the $A$ warehouse.

\section{FDMM METHOD}

The third method of assessment offers mutual comparisons of individual criteria. Subsequently, the pairs of different alternatives are compared according to individual criteria. The table shows comparison of pairs of assessment criteria under the FDMM method. Table 4 presents the assessment results based on the weighted sum method using the proposed criteria and the assignment of individual weights. Table 4 shows that the optimum warehouse is the A warehouse.

After making the weighted sum calculations, the results show that the best alternative for the given shipment is the $A$ warehouse.

\section{COMPARISON OF RESULTS OF DIFFERENT METHODS OF ASSESSMENT}

It is clear from comparison of the results of warehouse suitability assessment by the weighted sum method, the DMM method and the FDMM method, that the best alternative for transport of

Table 4 Results of the assessment by the FDMM

\begin{tabular}{|c|c|c|c|c|c|c|c|}
\hline \multirow{2}{*}{ Criteria } & \multirow{2}{*}{ Weightsaj } & \multicolumn{2}{|c|}{ Warehouse A } & \multicolumn{2}{|c|}{ Warehouse B } & \multicolumn{2}{|c|}{ Warehouse C } \\
\hline & & u1 & a1.u1 & u2 & a2.u2 & u3 & a3.u3 \\
\hline $\mathrm{K} 1$ - Warehouse location with respect to the customer & 0 & 0.333 & 0 & 0 & 0 & 0.667 & 0 \\
\hline K2 - Available infrastructure & 0.047 & 0.667 & 0.031 & 0 & 0 & 0.333 & 0.071 \\
\hline K3 - Technical equipment of the warehouse & 0.214 & 0.667 & 0.143 & 0 & 0 & 0.333 & 0.332 \\
\hline K4 - Transportation options & 0.095 & 0.667 & 0.063 & 0 & 0 & 0.333 & 0 \\
\hline K5 - Shipment time and flexibility & 0.143 & 0.667 & 0.095 & 0.333 & 0.048 & 0 & 0.071 \\
\hline K6 - Transport costs & 0.214 & 0.667 & 0.143 & 0 & 0 & 0.333 & 0.095 \\
\hline K7 - Storage costs & 0.286 & 0.667 & 0.191 & 0 & 0 & 0.333 & 0.713 \\
\hline Sum & $\Sigma 1.0$ & \multicolumn{2}{|c|}{0.666} & \multicolumn{2}{|c|}{0.048} & \multicolumn{2}{|c|}{0.285} \\
\hline Final order & & \multicolumn{2}{|c|}{1} & \multicolumn{2}{|c|}{3} & \multicolumn{2}{|c|}{2} \\
\hline
\end{tabular}

Source: authors 
given products is the A warehouse. This warehouse best meets the requirements in terms of warehouse equipment, time and speed of material delivery to the customer, and last but not least, the costs.

\section{WAREHOUSE ALLOCATION BY MEANS OF THE Cooper Iteration METHOD}

A calculation by the Cooper iteration method was chosen to allocate a suitable warehouse for A products during their combined transportation, based on obtaining $\mathrm{x}$-coordinates and $y$-coordinates for an optimally placed DC warehouse $[x, y]$. Derivation of the TTC function of $x=0$ and the derivation of the
TTC function of $y=0$ (1) must apply. A detailed procedure of applying this method to find the solution is given in [13].

$$
\frac{\partial T T C}{\partial x}=0 \quad \Lambda \quad \frac{\partial T T C}{\partial y}=0
$$

Four companies representing all customer groups $1 \div 4$ were included in the calculation. The calculation made use of the data relating to the quantity of transported material, the cost of transport to individual locations and the coordinates of all four locations where the companies are based, as per Table 5 . Calculated coordinate values of an optimally located warehouse are shown in Table 6.

Table 5 Quantities, transport costs and company coordinates used in the calculation

\begin{tabular}{|c|c|c|c|c|}
\hline Company No. & Mi $[\mathrm{t}]$ & $\mathrm{Ci}[€]$ & $\mathrm{xi}$ & $\mathrm{yi}$ \\
\hline 1 & 21467 & 23.10 & 12.3 & 10 \\
\hline 2 & 3958 & 27.90 & 9.3 & 7 \\
\hline 3 & 20975 & 23.50 & 2.5 & 5.7 \\
\hline 4 & 8904 & 12.90 & 9.5 & 0.8 \\
\hline
\end{tabular}

Source: authors

Table 6 Calculated coordinates of an optimal warehouse location

\begin{tabular}{|c|c|c|c|c|c|c|c|c|c|c|}
\hline & $x_{0}$ & $y_{0}$ & $x_{1}$ & $y_{1}$ & $x_{2}$ & $y_{2}$ & $x_{3}$ & $y_{3}$ & $x_{4}$ & $y_{4}$ \\
\hline $\mathrm{DC}_{1}$ & 0 & 0 & 5.95 & 5.97 & 6.32 & 6.69 & 6.8 & 6.90 & 6.66 & 6.90 \\
\hline
\end{tabular}

Source: authors

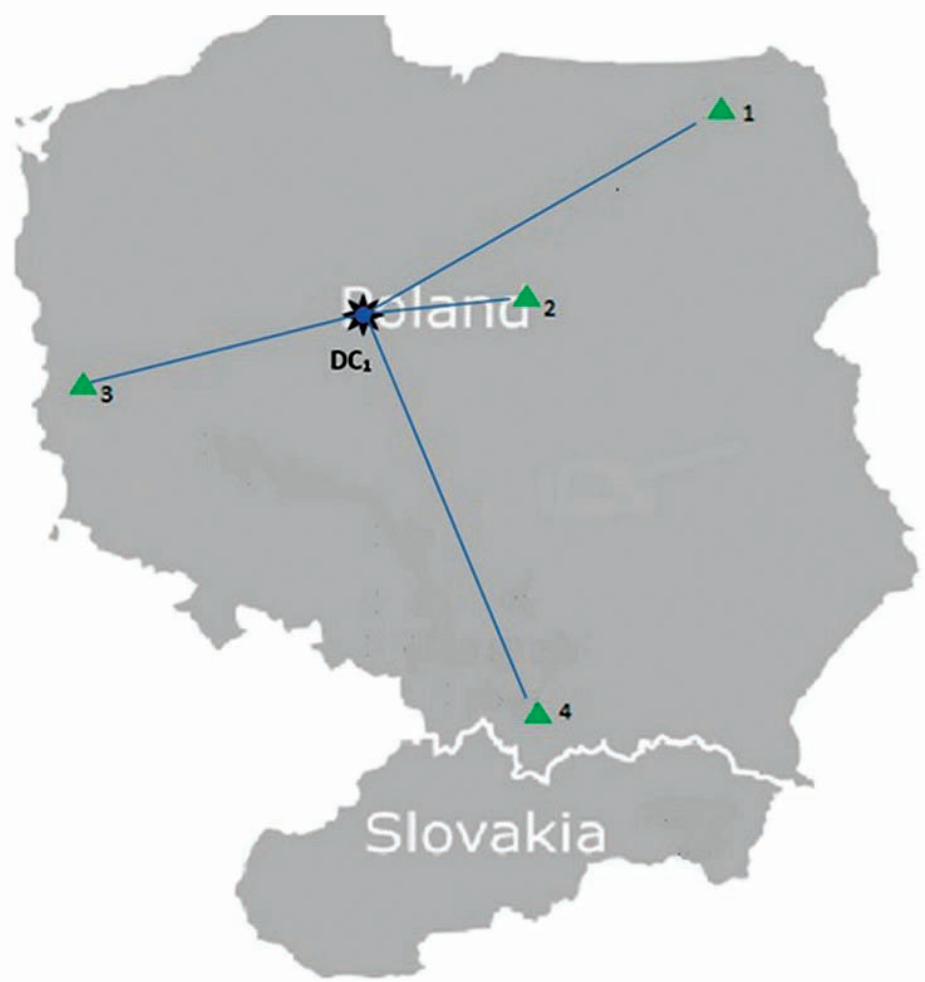

Source: authors

Figure 1 Optimum warehouse location map for delivering products to individual customers during combined transport with a link to a reloading terminal and a seaport 
Table 6 leads to a conclusion that the coordinates of an optimally located warehouse for $\mathrm{DC}_{1}$ products should be [6.66;6.90].

The warehouse coordinates derived from the calculation show the optimal location of the warehouse (Figure 1). From the given location, the costs of shipping and delivering from one warehouse to individual customers $1 \div 4$ will be optimal. In the future, larger supplies of material to customers $1 \div 4$ can be expected, which may require storage and gradual product shipments to customers exactly according to their requirements. If Just In Time requirements are to be catered to, the warehouse will be even better utilized to deliver fast and flexible shipments.

\section{CONCLUSION}

There is an ever-increasing need to transport growing volumes of goods in the world, and so we are looking for ever better ways and opportunities of how to meet this need. With its complexity of execution, combined transport certainly ranks among a higher form of transportation. Combined transport can rightly be classified as one of the best alternatives of delivering goods to the customers. High quality execution of combined transport requires a suitable warehouse linked to a reloading terminal and a seaport. In view of the growing customer demands for the services accompanying the goods, it is also necessary to look for the possibilities of providing such adequate service.

The selection and allocation of such warehouses provides more and more options and solutions in the form of integrated freight trains and regular container trains connecting seaports with reloading terminals, which significantly saves transport costs and allows for more route and freight combinations.

The paper shows how to select and situate a product warehouse for a selected sample of customers on the market. Such need can be expected in case of large and regular volumes. Due to the fact that at present the order for goods is placed with the producer who provides better service to the goods, more than just the material needs to be offered. One of the alternatives is, for example, storage of material outside the customer's premises with the possibility of a gradual and flexible removal of the material according to the current requirement for customer production and provision of Just in Time supplies with interconnection to the reloading terminal and the seaport.

\section{ACKNOWLEDGEMENT}

This work is a part of the following projects VEGA 1/0063/16, VEGA 1/0403/18, KEGA 018TUKE-4/2016, APVV 17-0235.

\section{REFERENCES}

[1] Buchmann, A., Pfohl, H.C., Appel, S., Freudenreich, T., Frischbier, S., Petrov I., Zuber, C. Event-driven services: Integrating production, logistics and transportation. In: Lect. Notes Comput. Sci. (Including Subser. Lect. Notes Artif. Intell. Lect. Notes Bioinformatics), 2011, pp. 237-241. https://doi. org/10.1007/978-3-642-19394-1_26

[2] Škrinjar, J. P., Abramović, B., Brnjac, N. The use of game theory in urban transport planning, Teh. Vjesn., 2015, vol. 22, pp. 1617-1621.

[3] Stopka, O., Kampf, R. Determining the most suitable layout of space for the loading units' handling in the maritime port, Transport., 2016, pp. 1-11. https://doi.org/10.3846/16484142.2016.1174882

[4] Strohmandl, J. Use of simulation to reduction of faulty products, UPB Sci. Bull. Ser. D Mech. Eng., 2014, Vol. 76, pp. 223-230.

[5] Sixta, J., Mačat, V. Logistika teórie a praxe, Computer press, Brno, Czech Republic. 2005.

[6] Torok, A. Comparative analysis between the theories of road transport safety and emission, Transport, 2017, Vol. 32, pp. 192-197. https://doi.org/10.3846/ 16484142.2015.1062798

[7] Beškovnik, B. Managing and Organizational Changes of Intermodal Network in Transition Regions: The Case of South-East Europe. Transport Problems, 2010, Vol. 5, No. 2, pp. 37-47. ISSN 1896-0596.

[8] Roso, V., Brnjac, N., Abramovic, B. Inland Intermodal Terminals Location Criteria Evaluation: The Case of Croatia, Transportation J., 2015, Vol. 54, pp. 496-515. https://doi.org/10.5325/transportationj.54.4.0496

[9] Lizbetin, J., Stopka, O. Practical application of the methodology for determining the performance of a combined transport terminal. In: 3rd Int Conf. Traffic Transp. Eng., Belgrade, 2016, pp. 382-387.

[10] Torok, A., Torok, A., Heinitz, F. Usage of production functions in the comparative analysis of transport related fuel consumption, Transp. Telecommun., 2014 Vol. 15, pp. 292-298. https://doi.org/10.2478/ttj-2014-0025

[11] Chovancova, M., Klapita, V. Draft Model for Optimization of the Intermodal Transport Chains by Applying the Network Analysis. In: 20th International Scientific Conference on Transport Means, Transport Means, 2016, Juodkrante, Lithuania, Oct. 05-07, 2016, pp. 112-116. ISSN 1822-296X.

[12] Chocholáč, J., Hrdý, D., Kuptcová, A., P. Průša. Factors affecting the warehouses location with accent on communication with the extern entities. Logi Scientific Journal on Transport and Logistics, 2016, Vol. 7, No. 1, pp. 18-26. ISSN 1804-3216.

[13] Straka, M. Distribution logistics (in Slovak), Epos, Bratislava, Slovak Republic 2013. 